\title{
ECONOMIA DE COMUNHÃO NA LIBERDADE PROMOVENDO O DESENVOLVIMENTO LOCAL SUSTENTÁVEL: CULTURA, GESTÃO E VALORES
}

\author{
ECONOMY OF COMMUNION IN FREEDOM PROMOTING SUSTAINABLE \\ LOCAL DEVELOPMENT: CULTURE, MANAGEMENT AND VALUES
}

\section{ECONOMÍA DE COMUNIÓN EN LIBERTAD PROMOVIENDO EL DESARROLLO LOCAL SOSTENIBLE: CULTURA, GESTIÓN Y VALORES}

\section{Recebimento: 11/03/2018- Aceite: 10/09/2018- Publicação: 28/10/2018}

Processo de Avaliação: Double Blind Review

Regina Maria da Luz Vieira ${ }^{1}$

Pós-Doutoranda Curso de Administração de Empresas

Núcleo de Estudos do Futuro (NEF)

Pontifícia Universidade Católica de São Paulo

regiluzvieira@uol.com.br

\section{Arnoldo José de Hoyos Guevara}

Doutorado em Estatística pela University of California System

Professor do Mestrado em Administração de Empresas da Pontifícia Universidade Católica de São Paulo

arnoldodehoyos@yahoo.com.br

\section{RESUMO}

Este trabalho traz o resultado da pesquisa realizada para identificar se e como práticas das organizações de Economia de Comunhão na Liberdade contribuem para promover uma cultura organizacional que possa contribuir no desenvolvimento local sustentável. A coleta de dados foi realizada a partir de pesquisa de campo quali-quantitativa com a aplicação de questionário fechado e entrevistas semiestruturadas para gestores e funcionários, e observação não participante. Os dados levantados e os resultados obtidos indicam que, mesmo tendo o propósito de partilharem o lucro e incidirem na sociedade de modo direto no espírito da Fraternidade, as empresas pesquisadas têm diferentes patamares de influência e, em alguns casos, é possível afirmar que esta influência é ainda pouco perceptível para a sociedade em geral.

Palavras-Chave: Economia de Comunhão (EdC), Fraternidade, Gestão baseada em Valores, Cultura, Desenvolvimento Local Sustentável

\footnotetext{
${ }^{1}$ Autor para correspondencia: Pontificia da Universidade Católica de Sâo Paulo - PUC- SP. Rua Ministro de Godoy, 969 - Perdizes . São Paulo -SP, 05014-90. Brasil.
} 


\begin{abstract}
This work brings the results of the research carried out to identify if and how the practices of the Economy of Communion in Freedom organizations contribute to promoting an organizational culture that may contribute to sustainable local development. The data was collected basically through a survey applying a closed questionnaire and semi-structured interviews for managers and employees. The analyses of data collected indicates that, even though they have the purpose of sharing profits and have some social impact fostering Fraternity, the companies surveyed have different levels of contribution and moreover, in some cases, it seems that this influence is still barely perceptible to society in general.
\end{abstract}

Key Words: Economy of Communion (EoC), Fraternity, Values Management, Culture, Local Sustainable Development

\title{
RESUMEN
}

Este trabajo trae el resultado de la investigación realizada para identificar si y como prácticas de las organizaciones de Economía de Comunión en la Libertad contribuyen a promover una cultura organizacional que pueda contribuir en el desarrollo local sostenible. La recolección de datos fue realizada a partir de la investigación de campo cual-cuantitativa con la aplicación de cuestionario cerrado y entrevistas semiestructuradas para gestores y funcionarios, y observación no participante. Los datos obtenidos y los resultados obtenidos indican que, aun teniendo el propósito de compartir el beneficio e incidir en la sociedad de modo directo en el espíritu de la Fraternidad, las empresas encuestadas tienen diferentes patrones de influencia y, en algunos casos, es posible afirmar que esta influencia es todavía poco perceptible para la sociedad en general.

Palabras Clave: Economía de Comunión (EdC), Fraternidad, Gestión basada en Valores, Cultura, Desarrollo Local Sostenible

\section{INTRODUÇÃO}

O desenvolvimento sustentável (Sachs, 2004) ocorre com a erradicação da pobreza na medida em que políticas universais e transversais são criadas para atender as necessidades específicas de grupos em situações de vulnerabilidade. O paradigma da Economia de Comunhão na Liberdade (EdC) que fortalece o Carisma da Unidade, é uma possibilidade para um salto qualitativo de vida para essas populações marginalizadas dado que está focando no princípio da Fraternidade. A pesquisa em empresas de pequeno e médio porte de diferentes setores mostra como uma nova visão cultural com resgate da ética socioambiental e política, e sustentabilidade organizacional estão de acordo com os princípios da EdC para o resgate da cidadania ativa de populações mais pobres. 
A trajetória da EdC inclui a cultura do partilhar, a humanização do lucro, a reciprocidade, o princípio da fraternidade, o desenvolvimento sustentável e gestão por valores (Bruni, 2002) considerando a realidade dos municípios das organizações pesquisadas, e Indicadores Sociais (Santaga) como o Índice de Desenvolvimento Humano (IDH), o Índice de Desenvolvimento Humano Municipal (IDHM), o Índice Multidimensional de Pobreza (IMP), e o Programa das Nações Unidas para o Desenvolvimento (PNUD) bem como conceitos e informações do Relatório Brundtlan sobre o desenvolvimento, conforme consta na Declaração Universal dos Direitos Humano das Nações Unidas. Nesse sentido o Movimento dos Focolares, presente em mais de 182 nações, representa uma contribuição humanizadora importante.

A pesquisa nas organizações selecionadas incluiu em seu delineamento, o conhecimento sobre o perfil dos municípios onde elas estão instaladas, bem como a sinergia dos seus stakeholders, e a inter-relação entre gestão e cultura. A metodologia da pesquisa envolveu estudo analítico quali-quantitativo com pesquisa de campo: análise qualitativa (técnica de análise de conteúdo) e quantitativa (análises multivariada, linear e de regressão), estudo multicasos e análise cruzada.

O estudo envolveu também uma pesquisa de campo no polo empresarial italiano Lionello Bonfanti, mostrando a experiência com o projeto de incubadoras e as várias propostas de ação de EdC para atingir a formação das futuras gerações de empresários, por meio de escolas, seminários e congressos promovidos pela EdC S.P.A (gestora do polo Lionello na Itália) e a Associação Nacional Por uma Economia de Comunhão (ANPECOM Brasil) que desenvolvem visitas e atividades conjuntas com as empresas coligadas - que não estão nos polos, mas integram os princípios da EdC - para atender as demandas.

A visão da EdC sobre os diversos stakeholders que compõem o raio de atuação das organizações é outra preocupação da pesquisa, além de sugerir uma proposta de comunicação integrada, a fim de contribuir para dar maior visibilidade às organizações e viabilizar parcerias futuras capazes de ampliar a ação social que propõe a EdC.

A pesquisa reuniu organizações de EdC entre cinco e vinte e quatro anos de existência, dirigidas por valores e conceitos que constituem a filosofia da instituição em coerência com a Carta de Princípios da EdC. As organizações pesquisadas procuram colocar em prática estes princípios na convivência cotidiana com os diversos segmentos sociais e pessoais, e desejam estimular uma mudança concreta de atitude. 


\section{A ECONOMIA DE COMUNHÃO NA LIBERDADE}

A EdC é um novo paradigma da humanização da economia e das organizações, que surgiu num contexto histórico mundial pós-queda do muro de Berlim, simbolizando a presença do comunismo e sua oposição ao capitalismo. No Brasil ela nasceu com as dificuldades econômicas causadas pela implementação do Plano Collor e, consequentemente, o aumento do contingente de necessitados por todo o país.

Chiara Lubich (humanista-cristã católica) fundadora do Movimento dos Focolares (surgido em 1943 e reconhecido pelo Vaticano como Obra de Maria), em sua visita ao Brasil em 1991, propôs o desafio da cultura do dar, do partilhar nas organizações, tendo como base um novo modelo de gestão e do lucro empresarial, na verdade, o pilar de um novo sistema econômico que não é capitalismo ou comunismo, mas sim comunhão na liberdade (Zappalà, 1992).

Na comunhão na liberdade (Sen, 2010), o excedente obtido pelas organizações da EdC apresenta os seguintes objetivos (Lubich, 2004):

1- assistir e suprir as demandas dos que passam necessidades;

2- desenvolver tecnicamente as empresas para que possam crescer e oferecer mais oportunidades de emprego; e,

3- ajudar na criação da nova cultura da partilha, isto é, criar "homens novos", capazes de gerirem organizações e bens numa forma que contribua para maior equidade social.

A EdC vivencia uma espiritualidade de comunhão que aplicada na vida civil, busca conjugar eficiência e solidariedade, visando à coletividade, o bem comum e a preservação do meio ambiente para todos. Os pobres representam oportunidade e não um problema, pois suas necessidades impulsionam os integrantes da $\mathrm{EdC}$ a serem mais solidários e fraternos. A reciprocidade que comporta a confiança, mesmo com riscos e custos para empresas e empresários, é um princípio da EdC que favorece um novo espaço no interior da atividade econômica de mercado e envolve três aspectos centrais: empresas, pobres e concorrentes. A proposta da EdC representa uma forma de superar os desafios da desigualdade social, da distribuição de renda e do desemprego estrutural; e está baseada na constituição de empresas ou na transformação das existentes que tenham como finalidade central gerar renda e lucro, realizar a distribuição, a comunhão dos lucros em três partes: 
1- Reinvestindo na própria empresa;

2- Investindo na formação cultural de modo a fortalecer e a difundir a cultura da partilha por meio de congressos, escolas formativas específicas, bolsas de estudo; e,

3- Compartilhando parte do lucro ou de seus excedentes com aqueles que estão em situação de pobreza, a fim de que possam viver dignamente, ajudando-os em seus projetos, sem limitar-se a dar apenas assistência financeira.

Nas organizações de EdC o ser humano é o foco central, uma vez que não basta apenas dividir o lucro em três partes: organização, necessitados e formação profissional e humana. Os diversos relacionamentos internos e externos, inclusive com os concorrentes, devem melhorar o intercâmbio econômico, cultural, social e político-pessoal.

Atualmente, existem mais de 800 empresas de EdC, sendo 501 na Europa; 43 no continente asiático; 34 na África (das quais 18 surgidas entre 2012 e 2014) e 292 no continente americano, demonstrando um novo crescimento destas empresas a partir de 2009, apesar da crise econômica. No Brasil as 170 empresas estão localizadas nas regiões sul, sudeste, norte e nordeste. Existem também sete polos produtivos: dois no Brasil, em Cotia, interior de São Paulo e Igarassu, no Recife (PE); um na Bélgica; um na Argentina; um na Itália; um em Portugal; um na Croácia. (Focolare Worldwide).

$\mathrm{Na}$ relação entre EdC, cultura do dar e, o desenvolvimento sustentável as atividades nas organizações necessitam ser vistas a partir das dimensões ecológica, econômica e social (Quartana, 1992). O que significa maximizar o lucro e os investimentos sem prejudicar o meio ambiente, levar em consideração a satisfação de funcionários, clientes e fornecedores, e conhecer os concorrentes (valor econômico). Na dimensão valor ecológico avalia-se o ciclo do produto ou serviço, utilizando práticas de produção e consumo interno que conduzam ao respeito do ambiente, e a empresa precisa tornar-se sustentável por si própria. A dimensão valor social não deve ser assistencialista, precisa oferecer condições de trabalho e formação integral para que o ajudado na EdC se torne protagonista do seu próprio desenvolvimento (Burckart, 2002).

\section{CULTURA E GESTÃO NA EDC}


Os dois documentos que direcionam o modelo de gestão das empresas de EDC são: a "Carta de Princípios" (Identidade) e as "Linhas para Conduzir uma Empresa de Economia de Comunhão" (Linee per condurre um impresa di Economia di Comunione) nos quais estão os pressupostos teórico-práticos com base na espiritualidade que permeia a proposta apresentada por Chiara Lubich.

Conforme a "Carta de Princípios", a EdC é uma realidade una e mundial, sendo coordenada por uma comissão internacional central e por comissões locais ligadas entre si pelo princípio da subsidiariedade. As organizações que aderem à EdC empenham-se nas ações e ideias para colocar em prática os valores da cultura da comunhão, do partilhar, do dar e da reciprocidade.

A EdC está presente em organizações produtivas de várias formas jurídicas: lucrativas ou não, empresas sociais e civis, cooperativas, associações. As organizações se comprometem com a geração de riquezas e criação de novos postos de trabalho, com criatividade e inovação, a fim de compartilhar o lucro para as ações de $\mathrm{EdC}$, e contribuir para a criação de polos empresariais, que tornam visíveis, a proposta nas regiões onde se situam, tanto no Brasil como em outros países.

Conforme o documento "Linhas para Conduzir uma Empresa de Economia de Comunhão", a gestão organizacional deve inspirar-se na fraternidade em todos os seus níveis. E para tanto as funções e os papéis nas empresas necessitam ser definidos de modo claro e objetivo com espírito de serviço e responsabilidade. A forma de administração deve ser participativa, e os objetivos empresariais devem ser compartilhados e avaliados com transparência, e cuidando da qualidade das relações entre todos os stakeholders.

A gestão das organizações de EdC deve trabalhar no sentido de que o lucro seja compartilhado visando diminuir a condição de pobreza imediata, no desenvolvimento da empresa para que esta possa gerar novos postos de trabalho, para melhorar a remuneração dos sócios e difundir a cultura do partilhar, os funcionários e empresários devem construir relacionamentos saudáveis com os stakeholders externos, inclusive com concorrentes e a administração pública, tendo em vista o bem comum.

O trabalho precisa ser compreendido como oportunidade de crescimento profissional, espiritual e ético, gerando empenho para melhorar a qualidade de vida e o respeito em todos os níveis. O trabalho deve ser considerado como a possibilidade de transformar a si mesmo em "pão" partilhado ou compartilhado. A formação oferecida pela organização necessita 
oferecer condições para o desenvolvimento integral dos colaboradores, e a comunicação interna e externa deve oferecer meios para a divulgação da cultura organizacional.

As organizações de EdC buscam atuar como uma comunidade que se propõe a interagir com a comunidade local onde está sediada, bem como com a sociedade em geral por meio dos bens, serviços e produtos que comercializam ou produzem, tendo como finalidade o uso do lucro para a geração de empregos diretos ou indiretos. Dentro deste contexto, as organizações de EdC devem participar de concorrências lícitas, respeitar a legislação do meio ambiente e buscar o desenvolvimento sustentável.

\section{METODOLOGIA DE PESQUISA}

A identificação dos fatores de EdC em organizações foi realizada a partir da abordagem de pesquisa quali-quantitativa. Os métodos e técnicas utilizados na pesquisa tiveram por objetivo estabelecer a relação entre valores, comportamentos e níveis de consciência (Castellani, 2006) nas organizações pesquisadas, definindo categorias excludentes, a partir dos parâmetros apresentados por Richard Barrett (2014) e de acordo com o modelo da Espiral Dinâmica Integral (SDI) (Castellani, 2006) que estabelece um conjunto de ferramentas de análise distribuído por cores em oito níveis principais de consciência, conforme figuras 1,2 e 3 abaixo.

As organizações participantes da pesquisa foram selecionadas de acordo com o seu tempo de vida e adesão à cultura de EdC. A fim de verificar a prática de EdC foram realizadas entrevistas com gestores e funcionários das empresas instaladas no Polo Empresarial Spartaco, situado no município de Cotia (SP), o primeiro polo a acolher as empresas de EdC que surgiram no país menos de um ano após ser lançada a proposta de criação destas organizações. Outras organizações pesquisadas estão situadas nos municípios dos Estados de São Paulo e Santa Catarina: Botucatu, São Paulo, Vargem Grande Paulista, Garuva e Joinville.

O estudo envolveu treze organizações que estão no mercado, e a maioria delas, há mais de vinte anos, e outras entre cinco e dez anos. As organizações são de pequeno e médio porte: uma escola, uma associação, seis indústrias (duas de reciclagem de ferro e metal, uma de produtos de limpeza, outra de produção de embalagem, uma produz tubulação e uma móveis), dois estabelecimentos comerciais (na área de alimentação e outro na área de 
produtos diversos). As outras empresas são da área de serviços: setor administrativo, fomento e contabilidade, transporte de cargas e fornecimento de pisos suspensos.

\section{Figura 1: Espiral Dinâmica Integral}

\begin{tabular}{|c|c|c|c|c|}
\hline \multicolumn{5}{|c|}{ ESPIRAL DINĀMICA INTEGRAL } \\
\hline Estágio & Aprendizado & Pensar & Valores & Motivaçảo \\
\hline Bege & Ambiente & Instintivo & Sobrevivência & Imediata \\
\hline Purpura & Tribai & Magico & Etrnicos & Seguranca \\
\hline Varmethe & Grapal & Egocentricas & Pader & Damiatacao \\
\hline Azul & Social & Absoluto & Universais & Verdade \\
\hline Laranja & Cultural & Materialismo & Cientifico & Riqueza \\
\hline Verde & Comunitario & Relativo & Cooperaçáo & Liberdade \\
\hline Amarelo & Existencial & Integral & Aceitaçäo & Autonomia \\
\hline Coral & Complexo & Hollistico & Espiritual & Integracto \\
\hline
\end{tabular}

Fonte: PCN

Figura 2: Crenças e Valores

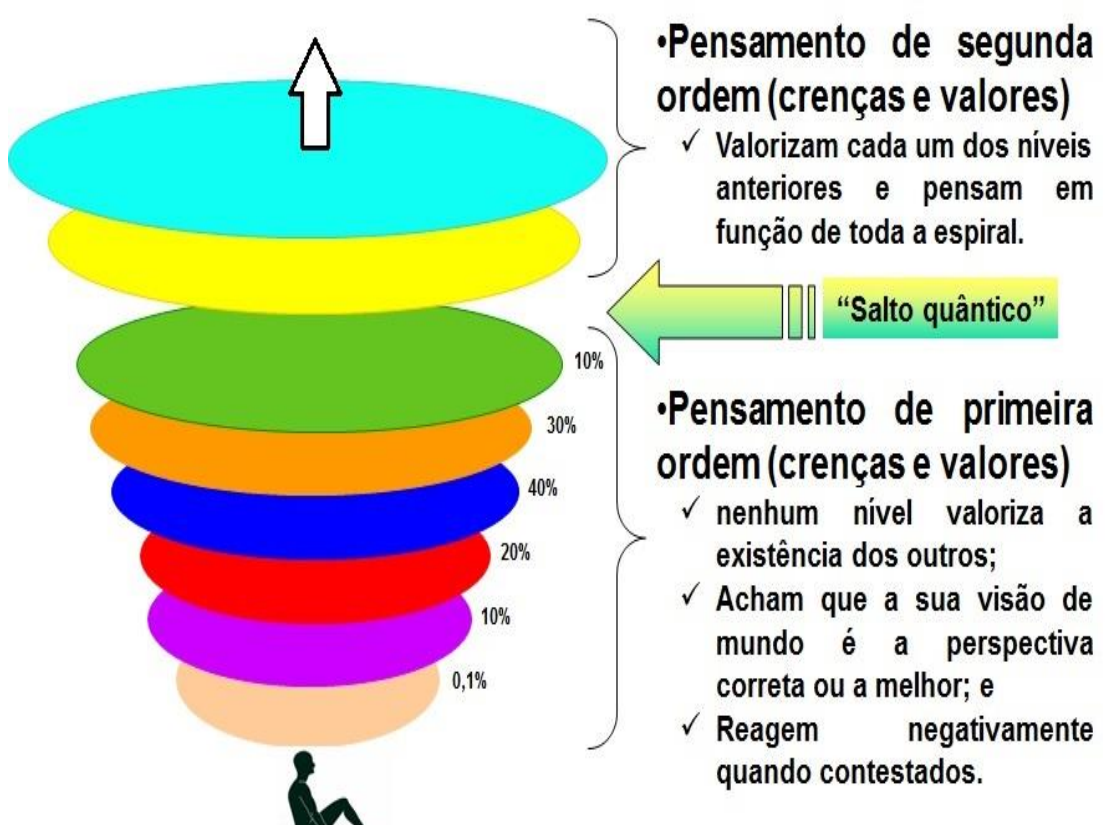




\section{Figura 3: Espiral Dinâmica (Spiral Dinamic)}

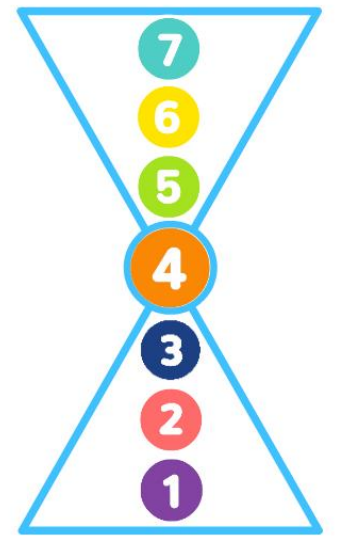

Servir

Fazer a Diferença Coesão interna Transformação Auto-Estima Relacionamentos Sobrevivência

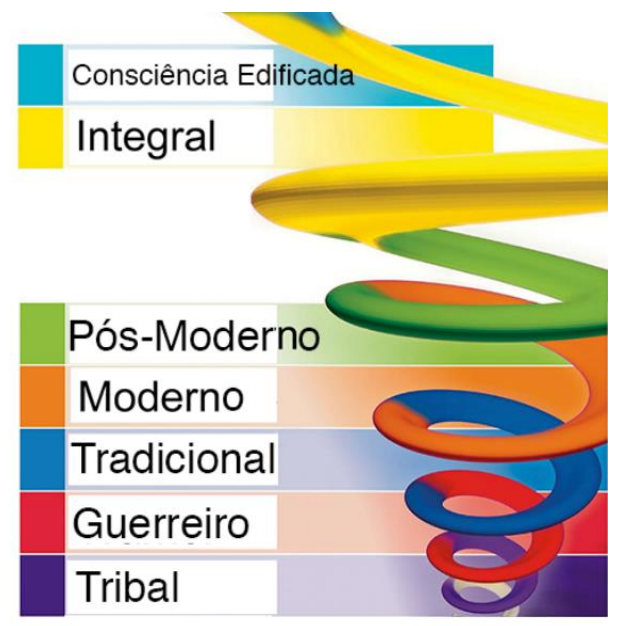

Fonte: Sociedade Global - SDI (Spiral Dinamic)

As entrevistas realizadas com gestores e funcionários das empresas do polo e algumas outras coligadas (oficialmente de EdC, porém, situadas fora do Polo Spartaco Lucarini devido às suas atividades) identificaram e avaliaram as suas cultura e gestão.

A análise qualitativa das entrevistas, a análise quantitativa dos questionários, e posterior triangulação dos dados obtidos, foram realizadas com base nos estudos metodológicos de Laurence Bardin (2009) e de Robert Yin (2004, 2010).

A pesquisa quantitativa utilizou para a coleta de dados primários um questionário fechado destinado aos funcionários contendo oitos questões subdivididas em diversos itens e categorias, e um questionário destinado aos gestores contendo quatorze questões subdividas em vários itens. A fim de efetuar a tabulação dos dados de ambos os questionários foi elaborada uma base de dados a partir da Escala de Likert, tendo como tratamento estatístico a frequência (1 a 5) e o agrupamento de variável, visando posterior análise de regressão multivariada, linear e de correlação dos dados.

A análise qualitativa utilizou o método de análise de conteúdo de Bardin, com a definição de categorias embasadas na teoria de Richard Barrett (ver The Barret Value Center) para avaliar organizações criadas e dirigidas por valores, e o estudo do nível de consciência baseada na Espiral Dinâmica (Castellani, 2006) e nas técnicas empregadas também por Barrett em seus estudos analíticos. A análise foi realizada a partir da condensação dos 
questionários e elaboração de categorias e subcategorias, definindo-se seis grandes aspectos: cultura organizacional, cultura organizacional e os princípios de $\mathrm{EdC}$, comunicação e relacionamentos, tipos de relacionamentos, principais desafios interno e externo e flexibilidade de horário, desenvolvimento sustentável e sustentabilidade. A sintetização de cada um destes aspectos processou-se com base na estipulação de unidades de contexto, traçando um paralelo entre trechos das falas dos funcionários e dos gestores para efetuar a triangulação com o quadro das novas palavras em EdC (indicadores de EdC) (Bruni, 2005).

A análise de conteúdo utilizou como unidades de contexto os temas obtidos das falas, gravadas e transcritas, dos entrevistados. Em seguida, foram estabelecidas as unidades de contextos para cada um dos seis grandes aspectos presentes nas questões abordadas, conforme roteiro pré-estabelecido, mantendo assim, as regras de homogeneidade e pertinência para este método de pesquisa e que é também uma técnica de análise de dados. Posteriormente, foi realizada a triangulação dos resultados e, em seguida, a inferência sobre os mesmos, a partir dos quadros demonstrativos gerados ao longo da análise.

\section{RESULTADO DAS ANÁLISES DE CONTEÚDO}

A pesquisa confirmou que a EdC é sempre uma experiência em curso, na medida em que surgem novas empresas e novos empreendedores que estão em busca de desenvolverem atividades empresariais que gerem não apenas benefícios materiais, mas bens relacionais, cujo custo não pode ser medido apenas pelo capital financeiro. Tais atividades implicam em valores organizacionais em encontro com as expectativas que integram os sete aspectos dos níveis de consciência apresentados por Richard Barrett (2014), em suas técnicas utilizadas para estudar organizações empresariais dirigidas por valores.

As empresas pesquisadas apresentaram níveis diversos de consciência no que se refere a gestores e a funcionários, inclusive dentro da mesma organização. Entretanto, grande parte dos gestores e funcionários situaram-se no nível 2 de consciência, ou seja, o foco está nos relacionamentos, tendo em vista construir relações internas capazes de criar senso de pertencimento. Alguns outros estão nos níveis 3, autoestima e 4, transformação, demonstrando o quanto estas organizações ainda estão nos níveis que envolvem os aspectos materiais, embora haja um direcionamento para os níveis superiores de consciência, cujo salto 
está exatamente no nível 4, o qual implica em fazer com que os membros do grupo tenham voz ativa nas decisões, contribuindo para alinhar visão, missão e valores da organização.

A análise quantitativa demonstra que as correlações presentes entre os valores adquiridos e os desejados, bem como a cultura organizacional e os princípios de EdC estão presentes no cotidiano das empresas pesquisadas. Isto transparece no quadro de coeficientes não padronizados no qual a variável que apresenta o maior poder de explicação é valores adquiridos e valores desejados, porque apresenta o maior valor da estatística. Esta variável independente comanda a correlação com a variável dependente cultura.

Segundo os dados levantados, e conforme aparece no capítulo 4 da versão final do trabalho realizado de pós-doutorado, no caso dos colaboradores a variável cultura - aspecto muito presente nas empresas de EdC - é explicada em boa parte através de uma Regressão

Linear Múltipla $\left(\mathrm{R}^{2}=82,6 \%\right)$ pelas variáveis independentes: Valores, Gestão e Desenvolvimento Sustentável; e nessa ordem de importância.

\section{POLO LIONELLO BONFANTI: ECONOMIA CIVIL E MUDANÇAS}

Um bom exemplo de aplicação da EdC nas organizações é o projeto de incubadoras, desenvolvido no Polo Lionello Bonfanti na Itália, perto de Florença. O Polo representa uma das atividades da economia civil que favorece mudanças futuras e inevitáveis dentro das organizações de EdC. A fim de estimular e auxiliar a abertura de empresas dentro desta filosofia, bem como acelerar este processo, como resposta à crise econômica mundial, a Associação Internacional de Economia de Comunhão (AIEC) e suas similares realizaram, em março de 2016, um encontro com representantes dos diversos conselhos de empresários para discutirem o referido projeto. A discussão teve como proposta a aplicação do projeto de acordo com a realidade e as necessidades de cada região ou país ali representado, e a confecção /atualização de uma cartilha simples, de comunicação fácil e universalizada.

Em função das atividades realizadas em diversas regiões, o International Incubating está se desenvolvendo de diferentes formas de acordo com o país. Quanto ao projeto de incubadora no Polo Lionello Bonfanti, inicialmente, ele foi subsidiado por empresários da Região da Toscana com o objetivo de agregar empreendedores dispostos a investirem na região e a realizarem uma experiência de incubadoras de empresas. A aprovação do projeto favoreceu a criação de startups, tendo como modo de agir a cultura da reciprocidade e, ao 
mesmo tempo, possibilitou que a EdC SPA pudesse prestar serviços de consultoria e assessoria aos novos negócios, sem custo, contribuindo assim para o crescimento empresarial da região. A EdC SPA administra cursos profissionais para gestores, funcionários e colaboradores.

O projeto recebeu financiamento até 2013. A maioria dos startups que surgiram neste período era de base tecnológica com espírito empreendedor, e buscava constantemente um modelo inovador de negócio. Segundo Gullo em entrevista, "as empresas que vêm para o polo precisam sentir se há sinergia seja pelo espaço econômico seja pelo aspecto criativo/inovativo, capaz de gerar contribuição, colaboração e sinergia, capaz de fazer frente a esta situação difícil de crise".

Em função da crise, outras empresas surgiram como é o caso de uma das empresas mais prósperas do Polo Lionello Bonfanti, que possibilitou nova perspectiva aos envolvidos, inclusive na vida profissional, ao mesmo tempo, outras empresas estavam fechando. Posteriormente, outras empresas deixaram o polo para se instalarem em várias outras regiões, em função da logística. Paralelamente, a crise impediu que algumas organizações que pretendiam expandir seus negócios fossem para o polo, o que poderia ter contribuído para maior desenvolvimento do polo.

Atualmente, a EdC SPA é uma organização que busca compartilhar conhecimento, ser competitiva externamente, preocupa-se com a proteção do meio ambiente (as leis italianas são severas neste aspecto), visa à lucratividade, emprega mão de obra local, visa o crescimento organizacional, o respeito e a confiança dos stakeholders, busca prosperidade, interatividade, inovação, solidez quanto ao mercado em que atua e dinamicidade, gestão humanizada com foco na pessoa e voltada para um ambiente de trabalho harmônico e coeso. A qualidade de vida é vista pela organização como muito importante envolvendo acesso à casa própria, emprego, trabalho e educação, assim como a qualidade nos relacionamentos de forma que as pessoas façam parte da estratégia da gestão e da dinâmica organizacional.

Quanto aos valores e comportamentos voltados para o desenvolvimento sustentável na empresa existem práticas para aproveitamento da luz solar (o que pode ser observado in locu), reciclagem e prevenção de acidentes de trabalho. A cultura do dar é vivenciada pela empresa por meio de um jogo chamado "Dado da Empresa" - diariamente uma frase de uma das faces do dado norteia os relacionamentos pessoais e grupais -, e participação em eventos como 
congressos, reuniões, palestras, festas e cursos internos. Este conjunto de atividades visa expandir a cultura extramuros.

A campanha de proteção ao meio ambiente e reciclagem são aspectos do desenvolvimento sustentável que ainda precisa de ação mais efetiva, enquanto a separação do lixo orgânico, a redução do uso de energia elétrica e prevenção de acidentes são práticas comuns para a organização, que busca ser geradora de novas oportunidades, diante da crise econômica mundial.

A qualidade do produto e o cumprimento de prazos são importantes desafios, assim como reciprocidade e transparência por parte dos concorrentes, a negociação com o governo, impostos e a questão da ética. Entretanto, não há relação direta ou indireta no tocante a sindicatos. Há desafios junto à sociedade em geral quanto a questões como participação nas decisões políticas, solidariedade, transparência, ética, divulgação da EdC e a cultura da partilha.

As empresas que se instalam no polo assinam um contrato de aluguel para garantir a prática de EdC com a sua ética e valores: cultura de participação, ética legal, gestão humanizada com foco principal no ser humano.

A comunicação dentro do polo ocorre por meio de e-mails e comunicados internos, comunicação direta e interpessoal. Segundo Gullo (2016) "Temos uma secretaria, que também é responsável pela comunicação com os empresários. Fazemos reuniões a cada 50, 60 dias, sendo um momento de troca, de partilha, de atenção à vida". A comunicação é importante porque se torna patrimônio de todos, buscando dar visibilidade para a sociedade sobre a experiência ali vivenciada. Neste aspecto, todos os empresários têm um site como instrumento informativo e de comunicação administrativa.

Gullo em entrevista afirma que "manter sempre alta a comunhão é um caminho em constante dinamicidade porque todos devem ser conscientes e corresponsáveis. Experimentamos que aquilo que vivemos não depende nunca de uma pessoa, mas depende de um corpo". Ela considera que compartilhar os valores éticos não apenas no aspecto legal, mas sobretudo, do ponto de vista humano e, vivenciá-los com os novos empresários que chegam ao polo é também um grande desafio, assim como a sustentação econômica das empresas que enfrentam diretamente o impacto da crise econômica mundial.

Ao longo dos dez anos de existência, o Polo Lionello Bonfanti se tornou referência para a constituição de empresas de EdC na Itália, tanto no aspecto gerencial como no de 
realização dos diversos cursos, as atividades empresariais passaram a incluir setores inovadores como é o caso de empresas de software. Enquanto empresas cresceram, outras deixaram o polo para se instalarem em regiões mais viáveis ao negócio, e outras deixaram de existir devido à crise.

\section{PERSPECTIVAS EM EDC NO BRASIL}

No Brasil, os esforços para prosseguir com o Programa de Fortalecimento de Negócios Inclusivos e de Comunhão, lançado em 2015, estão direcionados para pequenas empresas que atuam em situações de vulnerabilidade social, nas áreas de alimentação, educação, saúde e habitação. O programa também prossegue com iniciativas que oferecem oportunidades de desenvolvimento humano e social em favor das classes de baixa ou média renda e a indigentes.

A proposta se baseia em atividades que existem em outros países, e o financiamento e benefícios são vinculados à aderência às linhas gerais da EdC. O acompanhamento e análise das propostas estão sob a responsabilidade da ANPECOM. O programa recebeu 24 propostas das quais 10 foram pré-selecionadas para a oficina de empreendedorismo de comunhão, realizada em fevereiro de 2016, no Polo Empresarial Ginetta, em Igarassu, no Estado de Pernambuco.

O programa incentiva e fortalece negócios produtivos inclusivos, e tem a capacidade de propiciar a inserção econômica de pessoas empobrecidas ou em situação de vulnerabilidade social. O critério de classificação é determinado pela Associação Brasileira de Empresas de Pesquisa (ABEP), e inclui negócios que tenham como natureza a oferta de oportunidades de desenvolvimento humano e social. Anouk Grevin, representante da Comissão Internacional de EdC, ao concluir a Escola Interamericana da entidade, em outubro de 2015, na Mariápolis Ginetta, confidenciou que era viva a expectativa de que a escola fosse como um laboratório que pudesse abrir novos caminhos para a EdC, não só na América Latina, mas no mundo inteiro.

No evento de junho de 2016, na Itália, de acordo com dados do seu relatório final, foram constatadas duas necessidades comuns a todos os países: 1) incentivo e consolidação de uma segunda geração de empreendedores de EdC; 2) reformulação do modo de apresentar a EdC ao mundo, ou seja, da maneira de dialogar sobre EdC. Para concretizar ações visando 
atender e superar estes dois aspectos, no mesmo evento, foram estabelecidas duas diretrizes: 1- encontro de jovens representantes de todo o mundo na Summer School, também na Itália, no mês de setembro de 2016, para preparar uma nova proposta de apresentação da EdC para todo o mundo, a partir das sugestões de integrantes de EdC nos vários países. 2- criação e fortalecimento de uma rede internacional de incentivo a novas iniciativas empreendedoras de EdC que, em cada país, ganhará contornos próprios, conforme a realidade e capacidade local. Os países deverão buscar condições para custear suas propostas, no entanto, a Comissão Central (mundial) de EdC auxiliará com o que for necessário.

Com relação ao Brasil foram estabelecidas duas ações a serem articuladas pela ANPECOM: 1- relançamento da EdC nas comunidades com foco nas comissões locais e lideranças e formação na cultura de EdC para o fortalecimento das comissões existentes. A ANPECOM, em parceria com a Associação Mundo Unido (AMU), necessita promover visitas locais, encontros para a formação de líderes a fim de capacitar pessoas que acompanharão os empresários nas comunidades, e o recebimento dos recursos fornecidos dos projetos de assistência; 2- estruturação de uma rede no Brasil que favoreça o surgimento e a consolidação de empreendimentos de EdC. Neste sentido, serão estabelecidas parcerias entre a ANPECOM e instituições e com especialistas em aceleradoras e incubadoras, com iniciativas empreendedoras.

A ANPECOM deve promover parceria com instituições e especialistas em aceleradoras e incubadoras. À primeira cabe oferecer a formação cultural na EdC e às segundas cabe dar o conhecimento técnico de incubação e/ou aceleração de negócios, e a ANPECOM, junto com a AMU, cabe a consolidação e o reposicionamento do Programa de Fortalecimento de Novos Negócios Inclusivos de Comunhão. Objetivando atender as novas demandas, os dois polos empresariais do Brasil, Spartaco e Ginetta deverão ser reformulados.

\section{CONSIDERAÇÕES FINAIS}

As organizações de EdC nem sempre contribuem de forma concreta para o desenvolvimento e economia sustentável, pois a pesquisa verificou que pelo menos nas empresas analisadas não há um planejamento para este fim, apesar de apresentarem ações pontuais como economia de água, de energia e contenção de gastos. Entretanto, existem práticas colaborativas e individuais para a preservação do meio ambiente e consumo 
sustentável: reciclagem de papel e outros materiais de escritório, separação do lixo orgânico e do lixo reciclável. Algumas empresas estabeleceram contrato com associações vinculadas aos catadores de papel, papelão e outros materiais para reciclagem.

A cultura organizacional presente em EdC visa superar obstáculos nos relacionamentos entre os diversos stakeholders sejam eles internos ou externos, isto pode ser comprovado na relação positiva entre cultura, valores organizacionais e níveis de consciência, conforme a visão de Barrett, e dos níveis presentes na espiral dinâmica de acordo com o modelo expandido da Pirâmide de Maslow.

De acordo com a análise de conteúdo baseada em Bardin (2009), adaptada às técnicas de Barrett para estudar empresas dirigidas por valores, é possível afirmar que inclusive dentro de uma mesma organização gestores e funcionários têm níveis diversos de consciência. Porém, a maioria situa-se nível 2 de consciência, ou seja, os relacionamentos, tendo em vista construir relações internas capazes de criar senso de pertencimento. Alguns estão nos níveis 3, autoestima e 4, transformação, demonstrando o quanto estas organizações ainda estão em níveis básicos, embora já haja um direcionamento para os níveis superiores de consciência, cujo salto está no nível 4, o qual implica em fazer com que os membros do grupo tenham voz ativa nas decisões, contribuindo para alinhar visão, missão e valores da organização.

Segundo os dados levantados, a variável cultura, é muito presente nas empresas de EdC, e verificou-se forte correlação entre as variáveis: cultura atual, cultura desejada, valores organizacionais atuais e valores organizacionais desejados. No entanto, a correlação destas variáveis com a variável desenvolvimento sustentável é fraca.

É importante destacar que tanto as entrevistas quanto os questionários aplicados como técnicas para coleta de dados contribuíram para confirmar a forte preocupação de gestores e funcionários com a comunicação interpessoal junto aos diversos stakeholders, mas indicam também a inexistência de um planejamento estratégico no tocante à comunicação como meio de ação para divulgação da empresa ou da EdC junto ao público-alvo das organizações pesquisadas. As análises feitas identificaram a forte coesão de valores e princípios da EdC no cotidiano de gestores e funcionários, contribuindo inclusive para solução de conflitos e decisões gerais a serem adotadas internamente, e indicaram forte grau de alinhamento entre os valores individuais e coletivos junto aos stakeholders internos nos setores-chaves das organizações. 
A EdC SPA deixa claro estar muito comprometida com os princípios da EdC, sendo totalmente aberta ao diálogo, tendo o ser humano como foco a partir da valorização do outro, verificou-se nas respostas de outras organizações que ela é colaborativa, corresponsável, aberta ao aprendizado, cooperativa e transparente em suas decisões. Quanto à cultura organizacional interna apresenta não se mostra competitiva, apesar de ser colaborativa, visando o entrosamento, a valorização do outro, e ser transparente e fraterna.

Diante dos resultados aqui expostos surgem duas propostas de ação para as empresas de EdC, visando implementar sua incidência na sociedade e no mercado empresarial.

A primeira é a formação de um pool das empresas coligadas para elaboração de um planejamento estratégico de comunicação e marketing para o público-alvo externo, variando a ação conforme o segmento de mercado onde se inserem, e dando visibilidade aos diversos polos empresariais, a exemplo do que ocorre no Polo Lionello Bonfanrti.

A segunda linha de ação é desenvolver atividades internas que possam colaborar para que todos os envolvidos tenham clareza da missão, visão e valores da própria empresa, contribuindo para ampliar e modificar o nível de consciência dos stakeholders e alinhar estratégias e práticas cotidianas, conforme proposta de Barrett, tendo em vista melhorar o potencial humano e a lucratividade das organizações, tornando-as sustentáveis financeiramente.

$\mathrm{Na}$ perspectiva da EdC são necessárias profundas transformações no modo de conceber e pensar a economia, principalmente, no tocante à gestão e à distribuição do lucro, sem perder as dimensões humana, social e ambiental. As empresas necessitam de pessoas com nível de compreensão e consciência não restrito ao lucro. As encíclicas Laudato Si (Papa Francisco, 2015) e Enngelii Gaudium (Papa Francisco, 2013) fazem sugestões a respeito de uma economia de inclusão, que contribua para uma melhor distribuição da renda e dos recursos materiais do planeta como água, alimentação e energia, e para a construção de uma ordem social voltada ao bem comum. Não por acaso o próprio Papa Francisco continua reconhecendo o mérito do movimento que fortalece uma economia que tem como base a boa semente de comunhão.

\section{REFERÊNCIAS}


ANPECOM. Associação Nacional Por uma Economia da Comunhão. Disponível em $<$ http://anpecom.com.br/>.

BAGGIO, Antonio Maria (org.). O Princípio Esquecido/1. São Paulo: Cidade Nova, 2008.

BARDIN, L. Análise de Conteúdo. Lisboa, Portugal; Edições 70, LDA, 2009.

BARRETT, Richard. A Organização Dirigida por Valores: Liberando o potencial humano para a performance e a lucratividade. Rio de Janeiro: Elsevier / Campus, 2014.

Criando Uma Organização Dirigida por Valores: Uma abordagem sistêmica para uma transformação cultural. São Paulo: Antakarana e ProLíbera Editora, 2009.

Cultural Capital: A fundamental driver of financial performance. Disponível em: <http://www.valuescentre.com/uploads/2010-04-19/Cultural\%20Capital\%20$\% 20$ A $\% 20$ fundamental $\% 20$ driver\%20of\%20financial\%20performance.pdf $>$. Acessado em 22 jan. 2013.

Libertando a Alma da Empresa. Como transformar a organização numa entidade viva. São Paulo: Cultrix,1998.

BENITES, Riella Marcelo. Pessoas Que Fazem A Economia de Comunhão. São Paulo: Cidade Nova, 2009.

BRASIL 247, O seu jornal digital 24 horas por dia, 7 dias da semana. Disponível em: <http://www.brasil247.com/pt/247/brasil/147764/Brasil-reduz-pobreza-em-22-e-sobeposi\%C3\%A7\%C3\%A3o-no-IDH.htm >. Acessado em: dez. 2015.

BRASIL IDH. Brasil melhora IDH em 2014 mas cai uma posição no ranking mundial. Disponível em: <http://agenciabrasil.ebc.com.br/geral/noticia/2015-12/brasil-melhora-idh-em2014-mas-cai-uma-posicao-no-ranking-mundial> . Acessado em: mar. 2016.

BRUDTLAND, Gro Harlem. Relatório Brudtland - Our Commom Future. Disponível em: <https://ambiente.files.wordpress.com/2011/03/brundtland-report-our-common-future.pdf >.

Acessado em: 22 jan. 2013.2 Disponível em: <http://www.scielo.br/pdf/ram/v12n3/a02v12n3.pdf>. Acessado em: 10 fev. 2016.

BRUNI, Luigino. A Ferida do Outro - Economia e relações humanas. São Paulo: Cidade Nova, 2014.

Economia de Comunhão - Uma Cultura Econômica em Várias Dimensões.Vargem Grande Paulista: Cidade Nova, 2002. Nova, 2005.

Comunhão e as novas palavras em Economia. Vargem Grande Paulista: Cidade , PELligRA, Vittorio. Economia Come Impegno Civile. Roma: Città Nuova, 2002. 
Zamagni, Stefano. Economia Civil: eficiência, equidade, felicidade pública. Vargem Grande Paulista: Cidade Nova, 2010.

BURCKART, Hans. Desenvolvimento Sustentável e gerenciamento empresarial: elementos para um novo paradigma da gestão in Bruni, Luigino: Economia de Comunhão - Uma Cultura Econômica em Várias Dimensões, pp.67-87. São Paulo: Cidade Nova, 2002.

CARVAlHO, Hannah de. A Estratégia de Comunicação Organizacional, tendo como base a gestão de Valores. Dissertação (Mestrado em Administração de Empresas) Programa de Pós-Graduação em Administração de Empresas da PUC-SP, São Paulo, 2015.

CASTELLANI, Moacyr. Ken Wilber e a dinâmica da espiral. In: SIMPÓSIO NACIONAL SOBRE CONSCIÊNCIA, 1., 2006, Salvador. Anais... Salvador: Fundação Ocidemnte, 2006. 1 CD-ROM. Disponível em: <http://www.conscienciologia.pro.br/artigos_congressos/32.pdf>. Acessado em: 10 mar. 2013.

CATEDRA Ignacy Sachs. Guia Gestão Pública Sustentável - GPS, PUC SP <http://www.pucsp.br/catedraignacysachs/guia-gps.html>

CIDADES SUSTENTÁVEIS. Programa Cidades Sustentáveis. Disponível em <http://www.cidadessustentaveis.org.br/>. Acessado em: 12 set. 2016.

DA LUZ VIEIRA, Regina Maria. Economia de Comunhão na Liberdade (EdC) e Desenvolvimento Local Sustentável: Gestão, Cultura e Valores. Pós-doutorado FEA-PUCSP, 2017. Disponível em < http://www.pucsp.br/catedraignacysachs/downloads/economia-dacomunhao-relatorio.pdf $>$.

DOMENICO, Silvia Marcia Russi de. Valores Relativos à Competição Organizacional e Interações entre Stakeholders. Tese (Doutorado em Administração de Empresas) - Centro de Ciências Sociais e Aplicadas, Universidade Presbiteriana Mackenzie, São Paulo, 2007.

DOWBOR, Ladislau. Democracia Econômica: Alternativas de Gestão Social. Rio de Janeiro: Vozes, 2008. Disponível em: <http://dowbor.org/principais-livros/>. Acessado em: 8 fev. 2013.

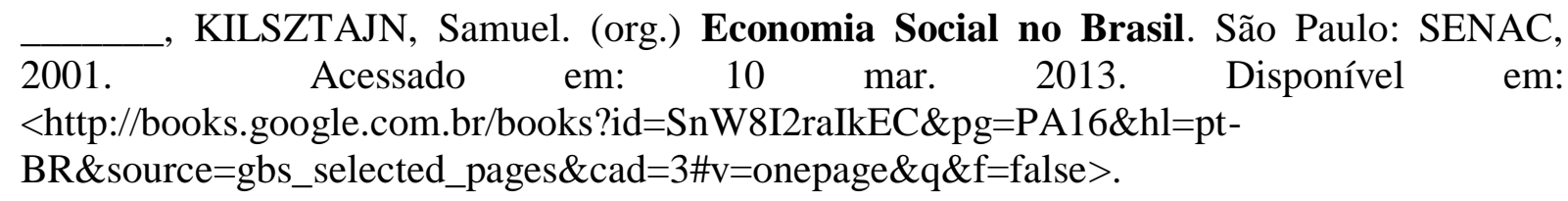

2008.

Democracia Econômica - Alternativas de gestão social. Rio de Janeiro: Vozes,

EDC. Economia da Comunhão - EdC. Disponível em <http://www.pucsp.br/catedraignacysachs/economia-de-comunhao.html>. 
Relatório Bi-Anual da Associação Internacional de Economia de Comunhão. Disponível em: <http://www.edc-online.org/>. Acessado em: 11 mar 2013.

FERRUCCI, Alberto. EdC: le sfide del duemila. Quaderni di Economia di Comunione, Roma, v.1, n.1, 1998.

FOCOLARES. Movimento dos Focolares Brasil. Disponível em http://www.focolares.org.br/> e em < http://www.focolare.org/>.

FOCOLARE WORLDWIDE. Movimento dei Focolari: Folcoare Worldwide. Disponível em <http://www.focolare.org/focolare-worldwide/ >.

FREITAS, Maria Ester de. Cultura Organizacional: Evolução e Crítica. São Paulo: Cengage Learning, 2012.

GALLAGHER, John; BUCKEYE, Jeanne. Structures of Grace - The Business Practices of the Economy of Communion. New York: New City Press, 2014.

GONÇALVES, Heloisa Helena A. Borges Q. Centralidade das empresas de economia de comunhão. In: Cadernos de Administração nº 01, jan/jun. 2008.

HOYOS, A. et al. Consciência e Desenvolvimento Sustentável nas Organizações. Rio de Janeiro: Campus, 2008.

LAS CASAS, Alexandre Luzzi; GUEVARA, Arnoldo José de Hoyos. Pesquisa de Marketing. São Paulo, Atlas, 2010.

LIMA, Roberta. Articulações em conjunto: $O$ financiamento da transição rumo ao desenvolvimento sustentável. Dissertação (Mestrado em Economia) - Programa de PósGraduação em Economia Política da PUC-SP, São Paulo, 2014.

LUBICH, Chiara. Economia de Comunhão: História e Profecia. São Paulo: Cidade Nova, 2004.

MEDRANO, Jorge Arturo Vilena. Comunicação Organizacional. Dissertação (Mestrado em Comunicação e Cultura) - Programa de Pós-Graduação em Comunicação da Escola de Comunicações e Artes da ECA/USP, São Paulo, 2003.

NOGUEIRA, Arnaldo Nogueira. Teoria Geral da Administração para o Século XXI. Ática, 2007.

ONU BRASIL. Conheça os 17 novos objetivos do desenvolvimento sustentável da ONU. Disponível em <https://nacoesunidas.org/conheca-os-novos-17-objetivos-dedesenvolvimento-sustentavel-da-onu/>. Acessado em: out. 2015.

ORIBER. Observatório da Rede Ibero Americana de Prospectiva. Disponível em: <http://www.pucsp.br/catedraignacysachs/oriber.html>.

PAPA FRANCISCO. Carta Encíclica Laudato Si. São Paulo: Paulus, Loyola, 2015. 
Exortação Apostólica Evangelii Gaudium. São Paulo: Paulos, Loyola, 2013.

- Discurso do Papa Francisco aos participantes no encontro promovido pelo Movimento dos Focolares. Disponível em < http://www.edc-online.org/br/home-br/eventosinternacionais/eocwiththepope/12838-discurso-do-papa-francisco.html>

PAPA Bento XVI II. Carta Encíclica Caritàs in Veritate. São Paulo: Edições Paulinas, 2012.

PAPA João Paulo II. Centesimus Annus. São Paulo: Edições Paulinas, 1991.

PEÇANHA, Reynaldo Schimer. Cooperativas de reciclagem na capital paulista: um estudo multicasos sobre a inclusão socioeconômica dos catadores de material reciclável. Dissertação (Mestrado em Administração) - Programa de Pós-Graduação em Administração de Empresas da PUC-SP, São Paulo, 2015.

PNUD - Programa das Nações Unidas para o Desenvolvimento. Disponível em: <http://www.undp.org/content/undp/en/home. html>. Acessado em: 14 set. 2016.

em: 14 set. 2016.

. Objetivos del Milenio ODM. Disponível em: <http://www.undp.org/>. Acessado

Os 17 Objetivos de Desenvolvimento Sustentável ODS. Disponível em: <http://www.pnud.org.br/ods.aspx>. Acessado em: 15 set. 2016.

POLO LIONELlO BONFANRTI. Polo Lionello. Disponível em

$<$ http://www.edconline.org/br/quem-somos/polos-produtivos/polo-lionello-pt-br-1.html>

PROGRAMA Países Sustentáveis. Guia GPS - Gestão Pública Sustentável. Disponível em: <http://www.pucsp.br/catedraignacysachs/downloads/pac3adses_sustentc3a1veis_gps.pdf>.

PUC-SP - CÁTEDRA Ignacy Sachs. Desenvolvimento Sustentável.

Disponível em: <http://ecossociodesenvolvimento.org/ecossociodesenvolvimento/>, <http://www.pucsp.br/catedraignacysachs/>. Acessado em: 15 set. 2016.

QUARTANA, Pino (Org). Economia de comunhão - propostas e reflexões para uma cultura da partilha, a "cultura do dar". Vargem Grande Paulista. São Paulo. Cidade Nova: 1992.

RELATÓRIO PNUMA. Nosso Futuro Comum - Relatório De Brundtland, 1987. Disponível em: <http://www.un-documents.net/ocf-02.htm>. Acessado em 12 set. 2016.

RIBER. Rede Ibero Americana de Prospectiva. Disponível em: <http://www.pucsp.br/catedraignacysachs/riber.html>. Acessado em: 12 set 2016.

SACHS, Ignacy. Desenvolvimento includente, sustentável, sustentado. Rio de Janeiro: Garamond / Sebrae, 2004. 
SANTAGA, Salvatore. Indicadores Sociais: Contexto Social e Breve Histórico. Disponível em: <file:///C:/Users/Regina/Downloads/758-3228-1-PB.pdf >. Acessado em: 29 fev. 2016.

SEN, Amartya. Desenvolvimento Como Liberdade. São Paulo: Companhia das Letras, 2010 .

SILVA, M. Luciane. The social in corporations. The possibility of being responsable or innovative. $\quad 2017 . \quad$ RISUS, Disponivel em: https://revistas.pucsp.br/index.php/risus/article/view/35684

SINGER, Paul. Introdução à Economia Solidária. São Paulo: Fundação Perseu Abramo, 2003.

SORGI, Tommaso. La cultura del dare. Rivista Bimestrale di Cultura Nuova Umanittà, ano XIV, marzo-giugno, n.80-81,Grottaferrata (Roma), 1992.

A Cultura do Dar. In Economia de Comunhão Propostas e Reflexões para uma Cultura da Partilha. Cadernos Humanidade Nova. Editora Cidade Nova: Vargem Grande Paulista, 1998.

SORBARA, Antonio Júnior. Gestão baseada em valores - O papel dos valores nas organizações, síntese e análise de três metodologias de implementação de gestão baseada em valores. Dissertação (Mestrado em Administração de Empresas) - Programa de PósGraduação da Escola de Administração de Empresas de São Paulo da Fundação Getúlio Vargas (FGV), São Paulo, 2004.

THE BARRET VALUE CENTRE. The Barret Model. Disponível em: <https://www.valuescentre.com/mapping-values/barrett-model >. Acessado em: fev. 2016.

VEIGA, José Eli da. Desenvolvimento Sustentável - o desafio do século XXI. Rio de Janeiro: Garamond / Sebrae, 2010.

YIN, Robert K. Estudos de caso: planejamento e métodos. Porto Alegre: Bookman, 2005.

Estudos de caso: planejamento e métodos. 4. Porto Alegre: Bookman, 2010.

ZAPPALÀ, Roberto. Comunismo - capitalismo - comunione. Riflessione in chiave antropológica. Rivista Bimestrale di Cultura Nuova Umanittà, ano XIV, marzo-giugno, n.80-81, Grottaferrata (Roma), 1992. 